\title{
Advance Care Planning Meets Group Medical Visits: The Feasibility of Promoting Conversations
}

\author{
Hillary D. Lum, $M D, P b D^{1,2}$ \\ Jacqueline Jones, $\mathrm{PbD}, \mathrm{RN}^{3}$ \\ Daniel D. Matlock, MD, MPH', \\ Russell E. Glasgow, $\mathrm{PbD}^{2,4}$ \\ Ingrid Lobo, $M D^{5}$ \\ Cari R. Levy, $M D, P b D^{6}$ \\ Robert S. Scbwartz, $M D^{1,2}$ \\ Rebecca L. Sudore, $M D^{7}$ \\ Jean S. Kutner, MD, MSPH \\ 'Division of Geriatric Medicine, Depart- \\ ment of Medicine, University of Colorado \\ School of Medicine, Anschutz Medical \\ Campus, Aurora, Colorado
}

${ }^{2}$ VA Eastern Colorado Geriatric Research Education and Clinical Center, Denver, Colorado

${ }^{3}$ College of Nursing, University of Colorado Anschutz Medical Campus, Aurora, Colorado

${ }^{4}$ Colorado Research in Implementation Science Program, Adult and Child Center for Health Outcomes Research and Delivery Science, University of Colorado School of Medicine, Anschutz Medical Campus, Aurora, Colorado

${ }^{5}$ Division of General Internal Medicine, Department of Medicine, University of Colorado School of Medicine, Anschutz Medical Campus, Aurora, Colorado

${ }^{6}$ Denver-Seattle Center for Veterancentered and Value-Driven Care, Denver, Colorado

${ }^{7}$ University of California, San Francisco Division of Geriatrics, VA Medical Center, University of California, San Francisco, California

Conflicts of interest: authors report none.

\section{CORRESPONDING AUTHOR}

Hillary D. Lum

12631 E. 17th Ave

Campus Mail Stop B179

Aurora, CO 80045

Hillary.Lum@ucdenver.edu

\begin{abstract}
PURPOSE Primary care needs new models to facilitate advance care planning conversations. These conversations focus on preferences regarding serious illness and may involve patients, decision makers, and health care providers. We describe the feasibility of the first primary care-based group visit model focused on advance care planning.
\end{abstract}

METHODS We conducted a pilot demonstration of an advance care planning group visit in a geriatrics clinic. Patients were aged at least 65 years. Groups of patients met in 2 sessions of 2 hours each facilitated by a geriatrician and a social worker. Activities included considering personal values, discussing advance care planning, choosing surrogate decision-makers, and completing advance directives. We used the RE-AIM framework to evaluate the project.

RESULTS Ten of 11 clinicians referred patients for participation. Of 80 patients approached, 32 participated in 5 group visit cohorts (a 40\% participation rate) and 27 participated in both sessions (an $84 \%$ retention rate). Mean age was 79 years; $59 \%$ of participants were female and $72 \%$ white. Most evaluated the group visit as better than usual clinic visits for discussing advance care planning. Patients reported increases in detailed advance care planning conversations after participating (19\% to $41 \%, P=.02)$. Qualitative analysis found that older adults were willing to share personal values and challenges related to advance care planning and that they initiated discussions about a broad range of relevant topics.

CONCLUSION A group visit to facilitate discussions about advance care planning and increase patient engagement is feasible. This model warrants further evaluation for effectiveness in improving advance care planning outcomes for patients, clinicians, and the system.

Ann Fam Med 2016;14:125-132. doi: 10.1370/afm.1906.

\section{INTRODUCTION}

$\mathrm{D}$ espite the benefits of advance care planning for patients, primary care clinicians face barriers to effective counseling on the issue, including their limited time and a lack of clinic-based support. ${ }^{1-4}$ The Dying in America report ${ }^{5}$ emphasized the need to integrate advance care planning into clinical care, and the Centers for Medicare and Medicaid Services recently approved reimbursement for counseling on advance care planning. ${ }^{6}$ Advance care planning is an ongoing process that involves multiple conversations among individuals, family members, and health care professionals. ${ }^{1,7}$ Studies show that many US decedents had not discussed preferences for end-of-life care with someone close to them, completed a living will, or established a durable power of attorney for health care. ${ }^{8,9}$

Primary care clinics are uniquely positioned to implement new models that engage patients in advance care planning. ${ }^{10}$ The American Academy of Family Physicians recognizes group medical visits (GMVs) as a strategic approach within the patient-centered medical home. ${ }^{11,12} \mathrm{GMVs}$, also called shared medical appointments, engage patients in health promotion and disease management. ${ }^{13-18}$ Older adults enrolled in chronic disease management GMVs showed improved health status, satisfaction with 
care, and self-efficacy, as well as decreased health care utilization..$^{19}$ Key GMV strengths include increased patient satisfaction, support for behavior change, and patient engagement. ${ }^{16,18}$

Given how GMVs support patient engagement through group interaction, we developed the first advance care planning group visit, the "Conversation Group Medical Visit." This model leverages group dynamic to transform the typical patient-clinician encounter related to advance care planning. This article describes a pilot demonstration of the new model.

\section{METHODS}

\section{Setting and Participants}

Seniors Clinic at the University of Colorado Hospital (Aurora, Colorado) is a patient-centered medical home that provides primary care for about 1,900 older adults. The team includes physicians and mid-level providers (11 clinicians representing 4.5 clinical fulltime equivalents), a social worker, nurses, pharmacists, medical assistants, and schedulers. Seniors Clinic patients average 83 years old $63 \%$ are female, $69 \%$ white and $13 \%$ black. Seniors Clinic has a long-standing, monthly GMV focusing on geriatric well-being. Building on this experience, we developed the Conversation GMV as a pilot demonstration project to promote advance care planning. The name reflects use of The Conversation Starter Kit as a teaching tool..$^{20}$ Results are from 5 cohorts who participated in visits between November 2013 and June 2014. This project was approved by the Colorado Multiple Institutional Review Board.

Patients could participate if they were aged 65 years or older, spoke English, and received primary care at Seniors Clinic. Patients were asked to participate if they were referred by their primary care clinicians, self-referred in response to clinicbased flyers, or were referred by a partner or friend. We encouraged clinicians to refer patients they felt would be able to participate in a group setting; that is, patients who did not have significant cognitive, hearing, or mental health impairments. We did not test the cognitive function of referred patients or exclude patients based on cognitive function. Clinicians were not asked to prioritize patients with poor health status, difficulty with advance care planning conversations, or known end-of-life needs. We sent referred patients an invitation letter and followed up by telephone to describe the program and schedule the 2 sessions. Our goal was to have 8 to 12 patients per cohort based on an estimate of appropriate size to foster group discussion around advance care planning.

\section{Conversation Group Medical Visit}

The Conversation Group Medical Visit aims to engage patients in a discussion of key advance care planning concepts and support patient-initiated advance care planning actions-choosing surrogate decision makers, deciding on preferences during serious illness, discussing preferences with decision makers and health care providers, and documenting advance directives in the electronic health record (EHR). ${ }^{21}$ The group visits involve 2 sessions of 2 hours each, 1 month apart, co-facilitated by a geriatrician and a social worker. Table 1 provides an overview of the GMV structure, facilitator considerations, session format, and documentation and billing details. The discussions include sharing experiences related to advance care planning, considering values related to serious illness, choosing surrogate decision makers, deciding how much flexibility

\section{Table 1. Conversation Group Medical Visit Structure}

\begin{tabular}{|c|c|}
\hline Structural Element & Content \\
\hline \multicolumn{2}{|l|}{ Overview } \\
\hline Sessions & Two sessions, 1 month apart \\
\hline Patients & Goal of 8 to 12 patients per cohort \\
\hline Practice setting & $\begin{array}{l}\text { A practice able to coordinate group medical visit processes } \\
\text { as a clinical team. }\end{array}$ \\
\hline Location & Clinic conference room \\
\hline Optional resources & Patient handouts; video projector; white erase board; water \\
\hline \multirow[t]{4}{*}{$\begin{array}{l}\text { Facilitator } \\
\text { considerations }\end{array}$} & $\begin{array}{l}\text { Facilitators need to represent } 2 \text { disciplines (physician and } \\
\text { social worker). }\end{array}$ \\
\hline & $\begin{array}{l}\text { One needs to be a physician, physician assistant or } \\
\text { advanced practice nurse able to bill for the medical visit. }\end{array}$ \\
\hline & $\begin{array}{l}\text { Facilitators must be able to facilitate a group and engage } \\
\text { patients in behavior change. }\end{array}$ \\
\hline & Facilitators must be knowledgeable in advance care planning. \\
\hline \multirow{7}{*}{$\begin{array}{l}\text { Group visit session } \\
\text { format }\end{array}$} & 2-hour sessions formatted as follows: \\
\hline & Arrival, check-in, medical update (30 minutes) \\
\hline & Introductions and rapport building (20 minutes) \\
\hline & $\begin{array}{l}\text { Advance care planning discussion using a communication } \\
\text { guide and decision aids ( } 60 \text { minutes) }\end{array}$ \\
\hline & Individual goal-setting (10 minutes) \\
\hline & Optional: Workshop time to complete advance directives \\
\hline & Optional: Individual clinical visits (10 minutes) \\
\hline \multirow[t]{3}{*}{$\begin{array}{l}\text { Documentation and } \\
\text { billing }\end{array}$} & $\begin{array}{l}\text { Document any individual evaluation and management ser- } \\
\text { vices provided (typically CPT code 99213). }\end{array}$ \\
\hline & $\begin{array}{l}\text { Update record with surrogate decision maker(s), care pref- } \\
\text { erences, advance directives, medical orders for scope of } \\
\text { treatment, code status preference as needed. }\end{array}$ \\
\hline & $\begin{array}{l}\text { Communicate advance care planning preferences with pri- } \\
\text { mary care provider. }\end{array}$ \\
\hline
\end{tabular}


to allow decision makers, and having conversations with decision makers and clinicians..$^{22,23}$ The facilitators aim to support an interactive discussion that affords opportunities for patients to learn from the experiences and perspectives of others. To support the facilitators' role, we developed a "Facilitators' Communication Guide" (Table 2), which is similar to other patient/provider communication guides. ${ }^{25}$ The Conversation GMV aims to help patients identify and achieve individualized goals related to advance care planning, including having conversations and choosing surrogate decision makers.

Like other group visit models, ${ }^{26}$ this GMV was integrated into the geriatric clinic using existing medical assistants and front desk staff for check-in processes. Patients sign a standard GMV clinical consent outlining their agreement to maintain privacy and acknowledging that routine co-payments apply. Patients receive an agenda for both visits, a personal copy of their EHR highlighting current advance care planning documentation, if any, and a blank medical durable power of attorney form. Facilitators use educational materials to guide the group discussion on advance care planning, including the Conversation Starter Kit, ${ }^{20}$ videos from the PREPARE website ${ }^{24}$ (http://www. prepareforyourcare.org) that demonstrate a family's

\section{Table 2. Facilitators' Communication Guide}

\begin{tabular}{|c|c|}
\hline Topic & Examples of Facilitator Questions and Sample Prompts \\
\hline \multicolumn{2}{|l|}{ Session 1} \\
\hline Introduction & $\begin{array}{l}\text { Today's goals are to talk about what's important to you for your } \\
\text { future health care choices and advance care planning. As we } \\
\text { start, can you introduce yourself and share why you chose to } \\
\text { come today? }\end{array}$ \\
\hline $\begin{array}{l}\text { Share advance care plan- } \\
\text { ning experiences }\end{array}$ & $\begin{array}{l}\text { Have you started thinking about what is most important to you? } \\
\text { Have you or someone close to you had experiences with serious } \\
\text { illness or death? }\end{array}$ \\
\hline \multirow[t]{2}{*}{ Consider personal values } & $\begin{array}{l}\text { Referring to the Conversation Starter Kit, "Consider 'what matters } \\
\text { to me is...' and 'what matters to me at the end of life is...'. What } \\
\text { do these questions bring up for you?" } 20\end{array}$ \\
\hline & What do you worry about concerning your health in the future? \\
\hline $\begin{array}{l}\text { Choose a surrogate deci- } \\
\text { sion maker(s) }\end{array}$ & $\begin{array}{l}\text { Who would be a good decision maker? Do you have a medical } \\
\text { durable power of attorney? Have you talked with him or her? }\end{array}$ \\
\hline Goal-setting & $\begin{array}{l}\text { Based on today's discussion, what goal do you have for between } \\
\text { now and next session? [Suggest identifying a surrogate decision } \\
\text { maker.] }\end{array}$ \\
\hline \multicolumn{2}{|l|}{ Session 2} \\
\hline $\begin{array}{l}\text { Review individual advance } \\
\text { care planning goals }\end{array}$ & $\begin{array}{l}\text { What was your goal regarding advance care planning or having a } \\
\text { conversation, and how did it go? }\end{array}$ \\
\hline $\begin{array}{l}\text { Consider flexibility in } \\
\text { decision making }\end{array}$ & $\begin{array}{l}\text { Let's watch videos from the PREPARE website. }{ }^{24} \text { This is about how } \\
\text { much flexibility you want a decision-maker to have. Do you want } \\
\text { him or her to have total flexibility, some flexibility, or no flexibility? }\end{array}$ \\
\hline $\begin{array}{l}\text { Consider future health } \\
\text { care choices }\end{array}$ & $\begin{array}{l}\text { Have you thought about the kind of care you would or would not } \\
\text { want to receive if you became very sick? }{ }^{24} \text { How much are you } \\
\text { willing to go through if it means you might have more time? }\end{array}$ \\
\hline $\begin{array}{l}\text { Plan for conversations } \\
\text { with health care } \\
\text { professionals }\end{array}$ & $\begin{array}{l}\text { How much does your primary care provider know about what's } \\
\text { important to you? What questions do you need to ask him or her? }\end{array}$ \\
\hline Goal setting & $\begin{array}{l}\text { What are your next steps regarding advance care planning? [Sug- } \\
\text { gest talking with a clinician.] }\end{array}$ \\
\hline
\end{tabular}

conversation, advance directives, and other resources, such as out-of-hospital orders. ${ }^{27}$ The Conversation Starter Kit is a handout that prompts individuals to think about their values and guides conversations about preferences. ${ }^{20}$ PREPARE is a website designed to help individuals prepare for medical decision making and has been shown to help older adults engage in advance care planning. ${ }^{24}$ Two of the authors, H.D.L. and R.S., established a licensing agreement between their respective institutions to support the use of PREPARE within this program. The GMV uses PREPARE videos showing various degrees of flexibility in the decision-making role.

After the group portion of the session, patients can request brief individual medical visits with the GMV physician to address acute medical issues. The GMV physician sends visit documentation via the EHR to each patient's primary care clinician with a description of the patient's perspectives on advance care planning, preferences for future health care choices, goals for advance care planning, opportunities for follow-up by the primary care clinician, and information about any acute medical issues present. The patient's EHR is updated with advance care planning preferences and documentation. The visits typically meet criteria for an established office visit of Current Procedural Terminology code $99213 .{ }^{28}$

\section{Implementation Strategy}

After developing the Conversation GMV, the facilitators, schedulers, medical assistants, and program assistants met to coordinate team members' roles in the clinic workflow. The geriatrician facilitator introduced the goals, structure, and referral process to clinicians and staff during regular meetings, developed an EHR-based referral order, and posted flyers in clinic rooms. We conducted an initial test cohort in September and October of 2013 before officially starting in November 2013. The test cohort included 8 patient volunteers who participated in 2 sessions to confirm that clinic staff could conduct the clinic workflow processes and facilitators could use the Facilitators' Discussion Guide before the start of the pilot study. 


\section{Evaluation Strategy}

We used the RE-AIM framework (Reach, Effectiveness, Adoption, Implementation, and Maintenance) to evaluate this pilot demonstration project. ${ }^{29,30}$ Using this framework, we addressed the following:

Reach: Will older adults participate in an advance care planning group visit?

Effectiveness: Will older adults engage in advance care planning conversations?

Adoption: Will providers refer patients?

Implementation: Will patients come to both sessions?

What aspects of advance care planning will older adults discuss in the GMV?

The maintenance portion of the RE-AIM framework was not evaluated in this pilot.

Data sources included GMV transcripts, patient demographics, and post-session evaluations that were managed using Research Electronic Data Capture (REDCap). ${ }^{31}$ Detailed project notes captured implementation efforts and outcomes. Referral and participation data included referral source (provider, self, partner/friend) and, among those who declined to participate, reasons for declining. For this pilot demonstration project, we developed and administered patient evaluations to collect demographic information, perspectives on the GMV using a 5-point Likert scale (adapted from author I.L.'s prior GMV evaluations), and assessed impact on advance care planning conversations (from The Conversation Project ${ }^{20}$ ). Specifically, after Session 1, patients were asked, "Prior to today's discussion about advance care planning, have you had this kind of conversation?" After Session 2, they were asked, "Did you have the conversation?" Patients could respond: "No," "No, but I have thought about it," "Yes, but at a general level," or "Yes. The conversations included enough details that I feel confident my loved ones know my wishes." A Wilcoxon signed-rank test was used to test for change in detailed advance care planning conversations before and after the GMV.

GMV sessions were audio recorded, transcribed, and analyzed using a mixed inductive and deductive approach. ${ }^{32}$ Data analysis involved systematic organization of the data through open coding, and repeated, constant comparison across coded data to identify consistent themes. ${ }^{33}$ We used a team approach to analysis, including regular meetings to discuss coded data and to reach consensus on identified themes and their meanings. Initial coding focused on the question, "What aspects of advance care planning will older adults discuss in the GMV?" We reviewed transcripts to catalog specific advance care planning topics, iteratively discussing the themes, interpretation, and potential implications of our findings using the qualitative analysis technique triangulation. Triangulation is a process of convening individuals with different perspectives to facilitate a deeper understanding and trustworthiness of the findings. Our authorship team includes geriatric palliative medicine specialists [H.L., R.S, C.L., and D.M.], a nurse qualitative researcher [J.J.], a group visit specialist [I.L.], implementation scientists [R.G. and D.M.], and academic leaders [R.S. and J.K.].

\section{RESULTS}

\section{Reach: Patient Participation}

We conducted 5 Conversation Group Medical Visit cohorts in Seniors Clinic (10 total sessions). Of 80 patients approached, 32 participated in at least 1 session, for a participation rate of $40 \%$. Mean age of participants was 79 years, 59\% were women, and $72 \%$ were white. Table 3 shows patient characteristics, referral sources, and, for patients who were approached but did not participate, reasons for not participating. Among 30 patients who declined to participate, reasons for declining included past advance care planning conversation or existing advance directive (30\%), lack of interest (13\%), illness (3.3\%), lack of transportation (3.3\%), and other/ unknown (50\%). While the goal was to schedule 8 to 12 patients per cohort, actual group sizes ranged from 4 to 9 patients due to patient cancelations.

\section{Effectiveness: Patient Acceptance of and Engagement in Advance Care Planning Conversations}

The majority of patients rated the Conversation Group Medical Visit as better than usual clinic visits for talking about advance care planning, thought they received useful information, felt comfortable talking about advance care planning in the group, and found talking with others about advance care planning to be helpful (Figure 1). Patients reported an overall increase in advance care planning conversations with loved ones after participating, including an increase in conversations with enough details that the patient felt confident that their loved ones knew their wishes ( $19 \%$ to $41 \%, P=.02$; Figure 2). Of 24 patients who reported having had an advance care planning conversation, $92 \%$ felt comfortable; $58 \%$ felt prepared, and $38 \%$ felt somewhat prepared.

\section{Adoption: Clinician Referral Patterns}

Ten of 11 clinicians referred at least 1 patient to the Conversation Group Medical Visit. The median number of referrals was 5, with a range of 1 to 23, where 23 patients were referred by the geriatrician project lead (H.D.L.). The second largest number of referrals from 1 clinician was 11 . More than $80 \%$ of participants were referred by their primary care clinicians (Table 3 ), though some self-referred or were referred by a partner 
or friend. Among GMV participants $(\mathrm{n}=32)$, there was a range of 0 to 5 patients per provider. Eight of 11 providers had at least 1 patient participate.

\section{Implementation: Patient Retention and Aspects of Advance Care Planning Discussed}

Patient retention was $84 \%$, with 27 of 32 patients participating in both sessions. One patient missed Session 1 but came to Session 2, making the total for that session 28 patients. Key discussion themes included sharing personal values and challenges related to advance care planning and discussing a broad range of patientraised topics related to advance care planning.

Theme 1. Patients Shared Personal Values and Challenges Related to Advance Care Planning The Conversation GMVs encouraged patients to share experiences related to advance care planning in the group setting. Patients told stories that reflected their personal values and challenges they had faced concerning serious illness or the experiences of loved ones as they approached death. In a discussion of future care preferences, some individuals had not thought much about what was important to them, while others had. One patient expressed her personal values:

We had this very discussion when a new [health care professional] came into my life and was just almost insisting that I have all kinds of tests and things. I don't want to live forever. I want to live when the quality of my life is in balance.

In the discussion about choosing a surrogate decision maker, some individuals said they had already made a choice and reported having completed formal documentation. For others, however, considering a surrogate was challenging because they weren't sure they could trust available surrogates to follow their wishes. One woman shared her challenges in considering her husband as her decision maker:

One of the things that surprised me was he said he didn't want to be the care agent. He didn't know if he could ask that things be removed. He is more emotional than I am.

Theme 2. Patients Initiated Group Discussions of a Broad Range of Advance Care Planning Topics The facilitated discussions introduced key advance care planning concepts (see Table 2, Facilitators' Communication Guide) and encouraged patients to share related experiences, questions, successes, and challenges. Beyond the topics raised by facilitators, patients in each session raised questions and concerns for discussion. Table 4 provides examples of the breadth of such topics. Many questions were practical, for instance about how to ensure that advance directives be available when needed. One patient asked,
The methods of getting that advance directive to the right person at the right time are not clear to me. How do they know? If you are 3 sheets to the wind, you can't do anything....You have to make arrangements before that happens.
Table 3. Characteristics of Conversation Group Medical Visit Participants Compared With Patients Who Were Approached But Did Not Participate

\begin{tabular}{|c|c|c|}
\hline Characteristic & $\begin{array}{l}\text { Participated } \\
(\mathrm{n}=32)\end{array}$ & $\begin{array}{c}\text { Did Not } \\
\text { Participate } \\
(\mathrm{n}=48)\end{array}$ \\
\hline Age, mean (SD), y & $79(5.3)$ & $78(6.8)$ \\
\hline Women, No. (\%) & $19(59)$ & $34(71)$ \\
\hline \multicolumn{3}{|l|}{ Race, No. (\%) } \\
\hline Native American & $1(3.1)$ & $\mathrm{N} / \mathrm{A}$ \\
\hline Hispanic or Latino & $1(3.1)$ & \\
\hline Black or African American & $7(22)$ & \\
\hline White (non-Latino) & $23(72)$ & \\
\hline \multicolumn{3}{|l|}{ Relationship status, No. (\%) } \\
\hline Married or with partner & $16(50)$ & $\mathrm{N} / \mathrm{A}$ \\
\hline Widowed & $9(28)$ & \\
\hline Divorced or separated & $4(13)$ & \\
\hline Single & $2(6.3)$ & \\
\hline \multicolumn{3}{|l|}{ Self-reported health status, ${ }^{a}$ No. (\%) } \\
\hline Excellent or very good & $13(42)$ & N/A \\
\hline Good, fair, or poor & $13(42)$ & \\
\hline $\begin{array}{l}\text { Caregiver for another person, } \\
\text { No. (\%) }\end{array}$ & $7(23)$ & N/A \\
\hline Attended with a partner, No. (\%) & $10(31)$ & N/A \\
\hline \multicolumn{3}{|l|}{ Type of insurance, ${ }^{b}$ No. (\%) } \\
\hline Medicare & $32(100)$ & $45(94)$ \\
\hline Medicare supplement & $14(44)$ & $21(44)$ \\
\hline Tricare & $17(53)$ & $19(40)$ \\
\hline Medicaid & $4(13)$ & $4(8.0)$ \\
\hline \multicolumn{3}{|l|}{ Education, No. (\%) } \\
\hline Less than high school graduate & $1(3.1)$ & N/A \\
\hline High school graduate/GED & $3(9.4)$ & \\
\hline Some college & $7(22)$ & \\
\hline College graduate & $7(22)$ & \\
\hline $\begin{array}{l}\text { Any postgraduate or } \\
\text { professional }\end{array}$ & $10(31)$ & \\
\hline \multicolumn{3}{|l|}{ Living situation, No. (\%) } \\
\hline Home or apartment & $27(84)$ & N/A \\
\hline Independent living community & $3(9.4)$ & \\
\hline \multicolumn{3}{|l|}{ Referral Source, No. (\%) } \\
\hline $\begin{array}{l}\text { Referred by primary care } \\
\text { clinician }\end{array}$ & $26(81)$ & $43(90)$ \\
\hline Self-referred & $3(9.4)$ & $0(0)$ \\
\hline Referred by partner or friend & $3(9.4)$ & $5(11)$ \\
\hline \multicolumn{3}{|l|}{ Reason for not participating, No. (\%) } \\
\hline Interested, but at a future date & $\mathrm{N} / \mathrm{A}$ & $2(4.2)$ \\
\hline Declined & N/A & $30(63)$ \\
\hline Unable to reach & $\mathrm{N} / \mathrm{A}$ & $3(6.3)$ \\
\hline $\begin{array}{l}\text { Scheduled but cancelled or } \\
\text { no show }\end{array}$ & $\mathrm{N} / \mathrm{A}$ & $13(27)$ \\
\hline $\begin{array}{l}\text { "At Session } 1 . \\
\text { bIncludes multiple payer sources when } \mathrm{k} \\
\text { "See text for reasons for declining. }\end{array}$ & & \\
\hline
\end{tabular}




\section{Figure 1. Patient experience of the conversation group medical visit.}

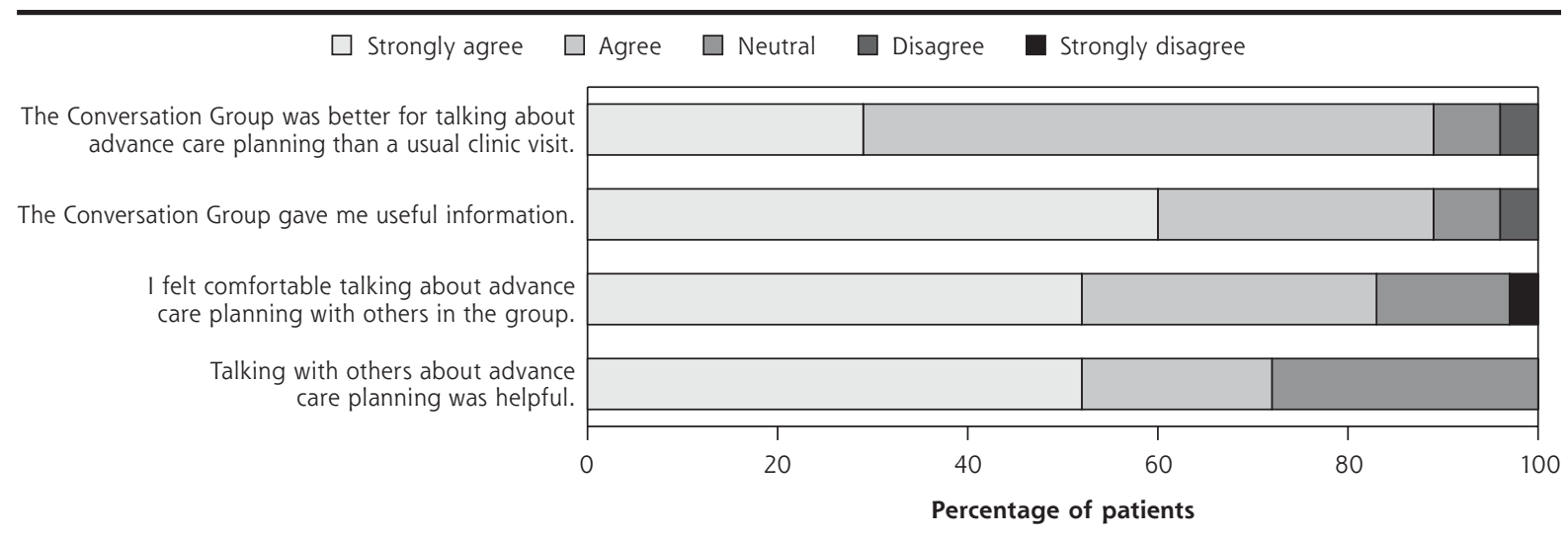

Note: Data are drawn from an evaluation that patients completed to assess their levels of agreement with 4 statements concerning acceptability of the Conversation Group Medical Visit. The evaluation used a 5-point Likert scale. ( $n=29 ; 2$ patients did not complete evaluations.)

In addition to questions about aspects of advance care planning, patients raised a broad range of topics pertinent to older adults with serious illnesses, including assisted living facilities, nursing homes, palliative care and hospice. One woman commented,

[My husband had] hospice in a nursing home. It was just wonderful....They just kept him very comfortable.... It was a beautiful death. It is a horrible thing to say, but it was a peaceful, wonderful end to his life.

Members of smaller cohorts (those of 4 to 6 patients), tended to mention fewer personal examples, ask fewer question, and discuss a smaller range of advance care planning experiences and topics than those in larger groups.

\section{DISCUSSION}

The Conversation GMV is a novel approach to facilitating advance care planning in primary care. The model uses the group visit to engage patients in detailed advance care planning conversations by providing a safe and supportive environment where patients share personal values and challenges and ask a range of questions related to advance care planning Older adults were willing to attend visits of this new clinical model, found it helpful, and were willing to share personal values and challenges related to advance care planning. Patients initiated discussions on a broad range of advance care planning topics. A GMV focused on advance care planning can tailor information and discussion to questions that patients consider important. Three-quarters of patients had advance care planning conversations after participating in Session 1, including $41 \%$ who had detailed conversations, and many reported feeling comfortable and prepared.
This GMV may influence outcomes that are important to patients and primary care clinicians. Potential patient-centered outcomes include improved satisfaction, knowledge, and motivation to participate in advance care planning. The GMV may facilitate advance care planning actions, including values clarification, conversations with surrogate decision makers and clinicians, and advance directive completion. It may also increase primary care clinicians' knowledge of their patient's wishes and their ability to provide medical treatment aligned with those wishes. Future work should formally evaluate the effects of the Conversation GMV on providers and clinic staff.

Some of the results suggest a need to understand barriers and facilitators to real-world implementation of the model. The $40 \%$ participation rate is higher than seen in other GMV studies involving older adults and other medical topics, suggesting that patients are inter-

\section{Figure 2. Patient engagement in advance care planning conversations.}

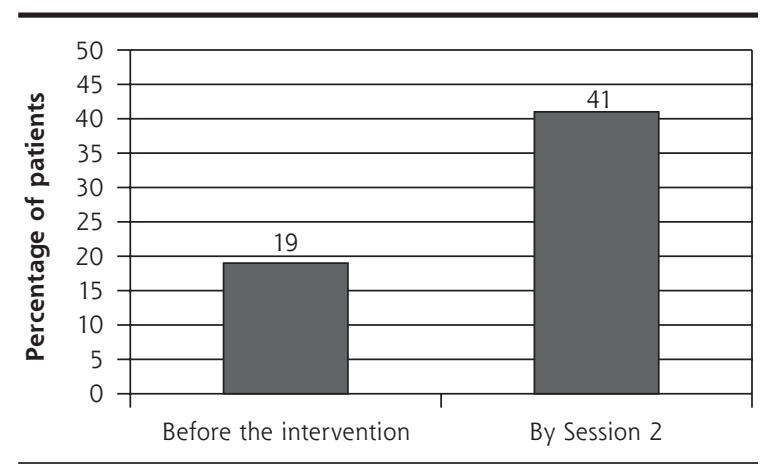

Note: During Session 1 and after participating in Session 2, patients were asked if they had had an advance care planning conversation. Bars represent the percentage of patients who answered, "Yes. The conversations included enough details that I feel confident my loved ones know my wishes." $(P=.02)$ 
ested and will participate in GMV on advance care planning. ${ }^{13,34,35} \mathrm{On}$ the other hand, the actual group sizes were lower than our goal and were limited by the rate of referrals, the number of patients who were unable to participate, and last minute cancelations and rescheduling. Patients in groups of 4 or 5 seemed less engaged in the discussion than those in groups of 7 or 9 patients, suggesting that group size may have an important effect on outcomes. Future cohorts could be over-scheduled by 2 or 3 patients given the frequent occurrence of last-minute cancelations. The Conversation GMV must also meet the needs of older patients with sensory, cognitive, and functional limitations, which is an issue beyond the scope of this pilot demonstration. ${ }^{36}$

Key barriers to future implementation may include the need for sustainable workflows for patient referral and scheduling as well as financial support for facilitator and staff training. Key factors promoting implementation may include strong, team-based interest in improving advance care planning, available clinic resources to conduct group visits (for example, meeting space, trained staff, and advance care planning patient education materials), and reimbursement models that support advance care planning and group-based care delivery.

The cost considerations of this model are similar to those of other GMVs. ${ }^{15,37}$ Potential financial challenges include adequate reimbursement for services, including patient co-payments, though multiple health care systems are successfully implementing and sustaining GMVs. ${ }^{15,25,36}$ The Conversation GMV can be facilitated by providers other than physicians, such as nurse practitioners or physician assistants, ${ }^{38}$ as long as they are trained in GMV facilitation and counseling in advance care planning. The Centers for Medicare and Medicaid Services recently approved payment for CPT codes for counseling in advance care planning, supporting the integration of advance care planning into clinical settings. ${ }^{6}$

Future evaluation should assess communication of patient preferences within the health care system, including documentation of advance directives. This project warrants formal evaluation, since it may be an effective model for integrating high-quality, patientcentered advance care planning into primary care.
To read or post commentaries in response to this article, see it online at http://www.annfammed.org/content/14/2/125.

Key words: advance care planning; group medical visits; patient engagement

Submitted July 14, 2015; submitted, revised, November 11, 2015; accepted November 24, 2015.

Funding support: This pilot demonstration project is supported in full or in part by The Colorado Health Foundation (\#5509), University of Colorado Hospital/University Physicians Incorporated Primary Care Strategic Initiative Fund, a Junior Faculty Career Development Grant from the National Palliative Care Research Center (NPCRC), and the Colorado Clinical \& Translational Sciences Institute (CCTSI) with the Development and Informatics Service Center (DISC) grant support (NIH/NCRR Colorado CTSI Grant Number UL1 RR025780) for use of REDCap-based data management. The sponsors had no role in the design, methods, or preparation of the manuscript. The views in this article are those of the authors and do not necessarily represent the views of the Department of Veterans Affairs.

Acknowledgments: The authors would like to thank John Scott, MD, a pioneer in group medical visits since 1991, who established and taught many patients and health care providers the value of the group medical visit, and has been discussing advance care planning in this context for over a decade. Dr Scott and Ingrid Lobo, MD, a current champion for group medical visit implementation at our institution, laid the 
foundation for the development of the Conversation Group Medical Visit. We also appreciate the excellent clinical work of the University of Colorado Seniors Clinic staff who assisted with implementation and conduct of this project. Additional special thanks to Sue Felton, MA, and Dana Lahoff, LCSW, for their tireless assistance with the development, implementation, and evaluation of this model in our local primary care setting.

Previous presentations: These results were initially presented at the 2015 American Academy of Hospice and Palliative Medicine Annual Assembly; February 25 - 28, 2015; Philadelphia, Pennsylvania.

\section{References}

1. Lum HD, Sudore RL, Bekelman DB. Advance care planning in the elderly. Med Clin North Am. 2015;99(2):391-403.

2. Fried TR, Bullock K, lannone L, O'Leary JR. Understanding advance care planning as a process of health behavior change. J Am Geriatr Soc. 2009;57(9):1547-1555.

3. Lund S, Richardson A, May C. Barriers to advance care planning at the end of life: an explanatory systematic review of implementation studies. PLoS One. 2015;10(2):e0116629.

4. Ahluwalia SC, Bekelman DB, Huynh AK, Prendergast TJ, Shreve S, Lorenz KA. Barriers and strategies to an iterative model of advance care planning communication. Am J Hosp Palliat Care. 2015;32(8):817-823.

5. Committee on Approaching Death: Addressing Key End of Life Issues. Institute of Medicine. Dying in America: Improving Quality and Honoring Individual Preferences Near the End of Life. Washington, DC: The National Academies Press; 2014.

6. Centers for Medicare and Medicaid Services. CMS Finalizes 2016 Medicare Payment Rules for Physicians, Hospitals \& Other Providers. https://www.cms.gov/Newsroom/MediaReleaseDatabase/Pressreleases/2015-Press-releases-items/2015-10-30.html. Published Oct 30, 2015. Accessed Oct 31, 2015.

7. Sudore RL, Schickedanz AD, Landefeld CS, et al. Engagement in multiple steps of the advance care planning process: a descriptive study of diverse older adults. J Am Geriatr Soc. 2008;56(6):1006-1013.

8. Bischoff KE, Sudore R, Miao Y, Boscardin WJ, Smith AK. Advance care planning and the quality of end-of-life care in older adults. J Am Geriatr Soc. 2013;61(2):209-214.

9. Silveira MJ, Kim SY, Langa KM. Advance directives and outcomes of surrogate decision making before death. N Engl J Med. 2010; 362(13):1211-1218.

10. Bleser WK, Miller-Day M, Naughton D, Bricker PL, Cronholm PF, Gabbay RA. Strategies for achieving whole-practice engagement and buy-in to the patient-centered medical home. Ann Fam Med. 2014;12(1):37-45

11. American Academy of Family Physicians. AAFP Policies. Shared medical appointments/group visits. http://www.aafp.org/about/ policies/all/shared-medical.html. Accessed Apr 17, 2015.

12. Martin JC, Avant RF, Bowman MA, et al.; Future of Family Medicine Project Leadership Committee. The Future of Family Medicine: a collaborative project of the family medicine community. Ann Fam Med. 2004;2(Suppl 1):S3-S32.

13. May SG, Cheng PH, Tietbohl CK, et al. Shared medical appointments to screen for geriatric syndromes: preliminary data from a quality improvement initiative. J Am Geriatr Soc. 2014;62(12):2415-2419.

14. Eisenstat SA, Ulman K, Siegel AL, Carlson K. Diabetes group visits: integrated medical care and behavioral support to improve diabetes care and outcomes from a primary care perspective. Curr Diab Rep. 2013;13(2):177-187.

15. Sikon A, Bronson DL. Shared medical appointments: challenges and opportunities. Ann Intern Med. 2010;152(11):745-746.

16. Jaber R, Braksmajer A, Trilling JS. Group visits: a qualitative review of current research. J Am Board Fam Med. 2006;19(3):276-290.
17. Kainkaryam V. The annual wellness visit shared medical appointment: innovative delivery of preventive care to the elderly. J Ambul Care Manage. 2013;36(4):335-337.

18. Cohen S, Hartley S, Mavi J, Vest B, Wilson M. Veteran experiences related to participation in shared medical appointments. Mil Med. 2012;177(11):1287-1292.

19. Beck A, Scott J, Williams $P$, et al. A randomized trial of group outpatient visits for chronically ill older HMO members: the Cooperative Health Care Clinic. J Am Geriatr Soc. 1997;45(5):543-549.

20. The Conversation Project. Welcome to the conversation starter kit. http://theconversationproject.org/starter-kit/intro/. Accessed Oct 13, 2012.

21. Sudore RL, Stewart AL, Knight SJ, et al. Development and validation of a questionnaire to detect behavior change in multiple advance care planning behaviors. PLoS One. 2013;8(9):e72465.

22. Sudore RL, Fried TR. Redefining the "planning" in advance care planning: preparing for end-of-life decision making. Ann Intern Med. 2010;153(4):256-261.

23. Fried TR, Redding CA, Robbins ML, Paiva A, O'Leary JR, lannone $L$. Stages of change for the component behaviors of advance care planning. J Am Geriatr Soc. 2010;58(12):2329-2336.

24. Sudore RL, Knight SJ, McMahan RD, et al. A novel website to prepare diverse older adults for decision making and advance care planning: a pilot study. J Pain Symptom Manage. 2014;47(4):674-686.

25. Bernacki RE, Block SD; American College of Physicians High Value Care Task Force. Communication about serious illness care goals: a review and synthesis of best practices. JAMA Intern Med. 2014;174(12):1994-2003.

26. Berger-Fiffy J. The "nuts and bolts" of implementing shared medical appointments: the Harvard Vanguard Medical Associates experience. J Ambul Care Manage. 2012;35(3):247-256.

27. Physicians Orders for Life-Sustaining Treatment (POLST) Paradigm. http://www.polst.org/. Accessed Jul 26, 2014.

28. Documentation Guidelines for Evaluation and Management (E/M) Services. https://www.cms.gov/Outreach-and-Education/MedicareLearning-Network-MLN/MLNEdWebGuide/EMDOC.html Accessed Apr 17, 2015.

29. Glasgow RE, Vogt TM, Boles SM. Evaluating the public health impact of health promotion interventions: the RE-AIM framework. Am J Public Health. 1999;89(9):1322-1327.

30. Glasgow RE. RE-AIMing research for application: ways to improve evidence for family medicine. J Am Board Fam Med. 2006;19(1):11-19.

31. Harris PA, Taylor R, Thielke R, Payne J, Gonzalez N, Conde JG. Research electronic data capture (REDCap)-a metadata-driven methodology and workflow process for providing translational research informatics support. J Biomed Inform. 2009;42(2):377-381.

32. Fereday J, Muir-Cochrane E. Demonstrating rigor using thematic analysis: A hybrid approach of inductive and deductive coding and theme development. Int J Qual Meth. 2010;5(1):80-92.

33. Crabtree BF, Miller WL. Doing Qualitative Research. 2nd ed. Thousand Oaks, CA: Sage Publications; 1999.

34. Scott JC, Conner DA, Venohr I, et al. Effectiveness of a group outpatient visit model for chronically ill older health maintenance organization members: a 2-year randomized trial of the cooperative health care clinic. J Am Geriatr Soc. 2004;52(9):1463-1470.

35. Riley SB. Improving diabetes outcomes by an innovative group visit model: a pilot study. J Am Assoc Nurse Pract. 2013;25(9):466-472.

36. Cherniack EP. The use of shared medical appointments in the care of the elderly. J Ambul Care Manage. 2014;37(1):32-37.

37. Sieber WJ, Newsome A, Fiorella M, Mantila H. Translating patient self-management research into primary care: challenges and successes with group medical visits. Transl Behav Med. 2012;2(4):535-542.

38. Watts $S A$, Gee J, O’Day ME, et al. Nurse practitioner-led multidisciplinary teams to improve chronic illness care: the unique strengths of nurse practitioners applied to shared medical appointments/ group visits. J Am Acad Nurse Pract. 2009;21(3):167-172. 